\title{
Nevo Sebáceo de Jadassohn em Recém-Nascido
}

\author{
Nevus Sebaceous of Jadassohn in the Newborn
}

Andreia MEIRELES ${ }^{1}$, Marta PEREIRA², Maria José COSTA ${ }^{3}$
Acta Med Port 2020 Apr;33(4):288-288 $\cdot$ https://doi.org/10.20344/amp.12164

Palavras-chave: Nevo Sebáceo de Jadassohn; Recém-Nascido

Keywords: Infant, Newborn; Nevus, Sebaceous of Jadassohn

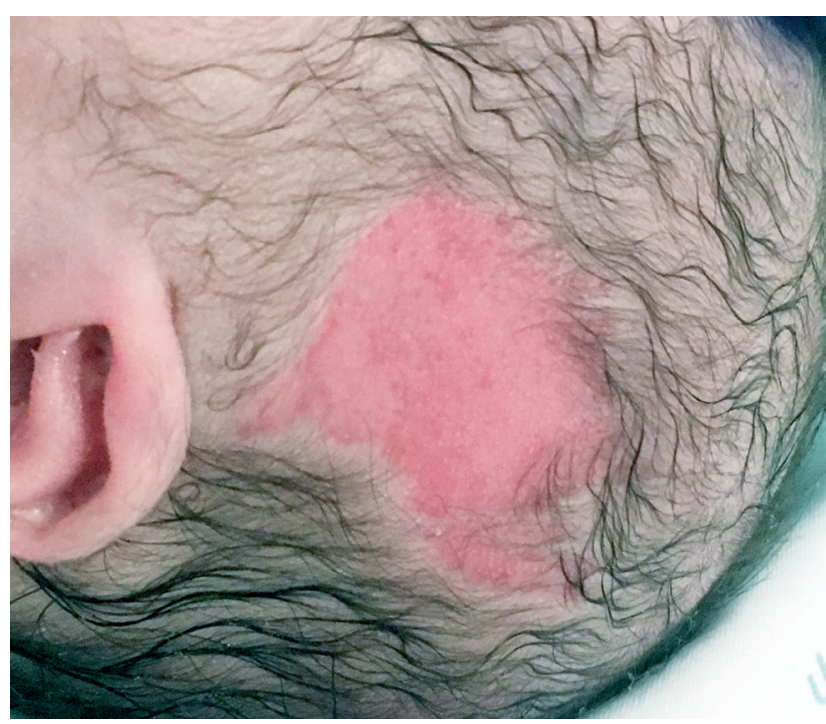

Figura 1 - Placa alopécica, ovalada, de tonalidade rosa-alaranjada, na região temporal esquerda, com $3 \mathrm{~cm}$ de maior diâmetro

Recém-nascido do sexo feminino, gestação de 39 semanas, vigiada e sem intercorrências. Ao nascimento detetou-se placa alopécica, ovalada, de tonalidade rosa-alaranjada, na região temporal esquerda, com $3 \mathrm{~cm}$ de maior diâmetro (Fig.1), compatível com nevo sebáceo de Jadassohn. Aos 11 meses, mantinha placa alopécica, ovalada, com tonalidade alaranjada (Fig. 2).

O nevo sebáceo de Jadassohn ou nevo organóide é uma lesão hamartomatosa congénita, rara, ${ }^{1}$ não hereditária, de causa desconhecida, caracterizando-se por um crescimento anormal das estruturas pilosebáceas e apócrinas. ${ }^{2}$

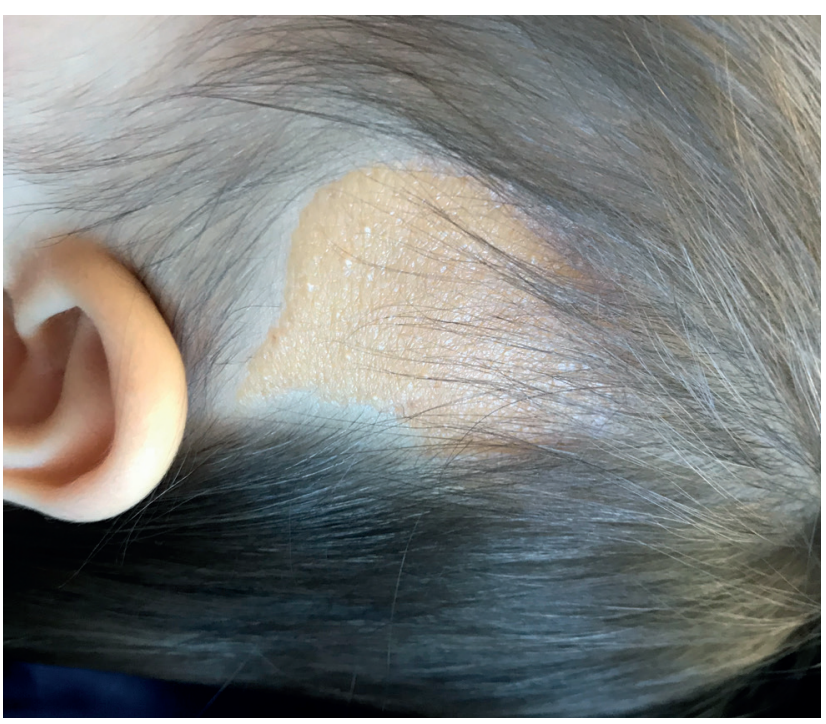

Figura 2 - Placa alopécica, ovalada, com tonalidade alaranjada

Habitualmente está presente ao nascimento e localiza-se preferencialmente no couro cabeludo. ${ }^{3}$ Clinicamente caracteriza-se como uma placa alopécica macia, alaranjada, de configuração ovalada ou linear, com dimensões variáveis entre $1 \mathrm{a} 10 \mathrm{~cm} .{ }^{1}$ É uma entidade cuja abordagem assenta essencialmente na vigilância clinica e dermatoscópica e na tranquilização parental, tendo em conta a benignidade da lesão. O surgimento de neoplasias é raro e a excisão cirúrgica é apenas recomendada nesta situação ou por motivos estéticos.

PROTECÇÃO DE PESSOAS E ANIMAIS: Os autores declaram que os procedimentos seguidos estavam de acordo com os regulamentos estabelecidos pelos responsáveis da Comissão de Investigação Clínica e Ética e de acordo com a Declaração de Helsínquia da Associação Médica Mundial.

CONFIDENCIALIDADE DOS DADOS: Os autores declaram ter seguido os protocolos do seu centro de trabalho acerca da publicação de dados.

CONSENTIMENTO INFORMADO: Obtido.

CONFLITOS DE INTERESSE: Os autores declaram não ter qualquer conflito de interesse relativamente ao presente artigo.

FONTES DE FINANCIAMENTO: Sem fontes externas de financiamento para a realização deste artigo.

\section{REFERÊNCIAS}

1. Moreno Alonso de la Celada R, Floristán Muruzábal U, de Lucas Laguna R. Nevo sebáceo de Jadassohn. An Pediatr. 2009;70:391.

2. Moody MN, Landau JM, Goldberg LH. Nevus sebaceous revisited. Pediatr Dermatol. 2012;29:15-23.

3. Soares DB, Cabral F, Nóbrega MM, Obadia DL, Silva RS. Apresentação atípica e exuberante de nevo sebáceo de Jadassohn. Surg Cosmet Dermatol. 2018;10:48-51. 